
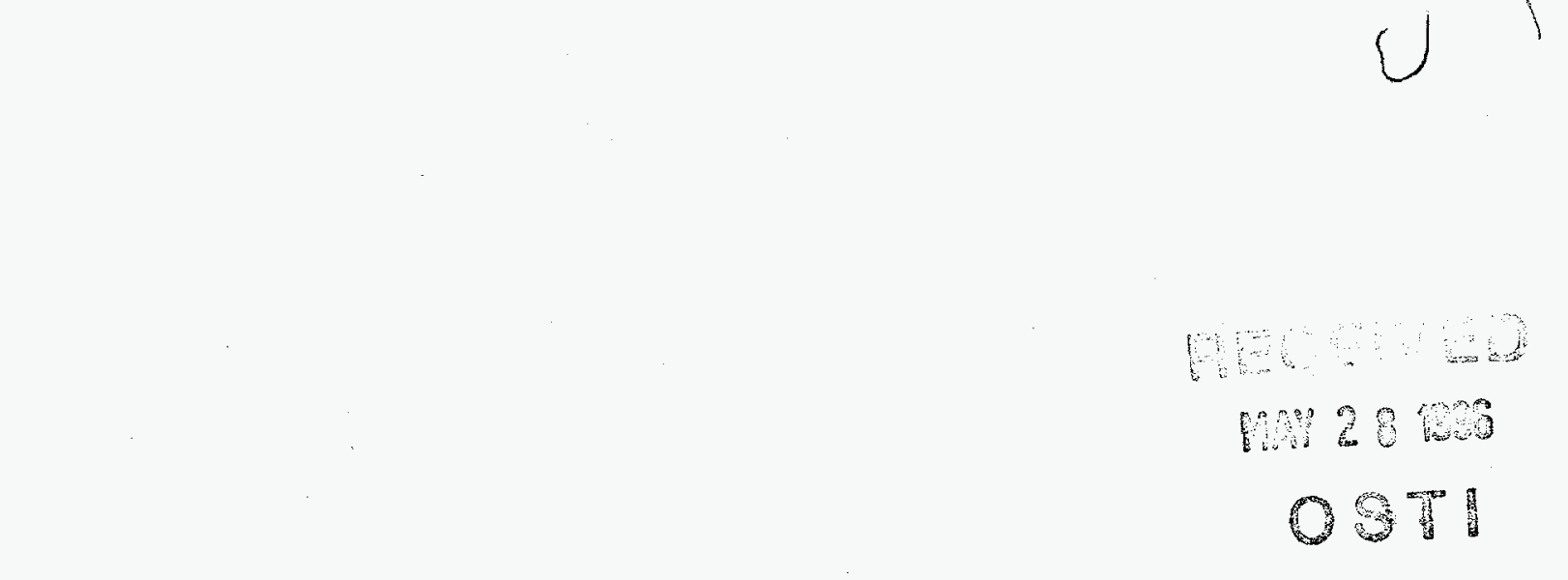

\title{
The Concept of Externality:
Implications for TVA Environmental
Research Center \\ The Concept of Externality:
Implications for TVA Environmental
Research Center \\ The Concept of Externality:
Implications for TVA Environmental
Research Center
}

by

Thomas H. Foster Agricultural Economist

TENNESSEE VALLEY AUTHORITY Environmental Research Center

Z-358 Muscle Shoals, Alabama June 1994 


\section{DISCLAMMER}

Portions of this document may be illegible in electronic image products. Images are produced from the best available original document. 


\title{
THE CONCEPT OF EXTERNALITY: IMPLICATIONS FOR
}

IVA ENVIRONMENTAL RESEARCH CENTER

\author{
Introduction
}

\section{Background}

Pollution of the environment is a result of the economic activities of production and consumption. And although the market system is touted as the superior method of organizing and operating an economic system, society frequently is dissatisfied with some of the side effects. In these cases of market failure, a cry for intervention of ten is raised to obtain more socially-desirable solutions. Environmental pollution is one symptom of market failure.

If the TVA Environmental Research Center is to focus on defining solutions to environmental problems and designing policy options for implementing such solutions, its efforts should benefit from an understanding of why the market fails and how it may be "adjusted" to produce more sociallydesirable results. Understanding the concept of externality is an appropriate starting point.

\section{Purpese and Scope}

The purposes of this discussion document are to:

1. Promote an appreciation for and understanding of the concept of externality (i.e., a "working" knowledge of the term and embodied concepts).

2. Demonstrate the utility of the concept in the design and packaging of policy and technology for improved environmental performance.

3. Provide a brief summary of the externality valuation issue currently being debated by the electric power industry.

4. Identify environmental research and development agenda opportunities or strategic considerations suggested for the Center by this review.

This paper is not intended to be an exhaustive and definitive academic study of externality-from theoretical origins in economic history through today's cutting-edge applications. But rather the document has been prepared to serve as an educational piece for a non-economist, broad-based audience. However, some elementary economic theory background must be given since much of the current electric power industry debate over environmental externality evaluation hinges on theoretical fine-points. 


\section{Externality Defined and the Economics of Pollution}

The concept of externality is closely tied to the concept of rational economic behavior. Heroically summarized, rational economic behavior holds that, on average, the production and consumption decisions of private individuals and firms are guided by revenues/benefits and costs, reflecting values derived from market activities (buying and selling). Market signals (prices) prompt production or consumption decisions to maximize personal welfare by balancing personal or private benefits and costs. In general, decisions based on market signals result in the most efficient allocation of scarce resources among competing ends. However, the market values or prices will not normally reflect the costs and benefits that are imposed on third parties.

Third-party costs and benefits are external to market actions and external to the private firm's or individual's profit and loss statement. Because these costs and benefits are imposed on or accrued to someone else (or society), they are not internal to decisionmaking and therefore are treated as irrelevant or having a price of zero. Externalities then are the costs or benefits of a market activity (production or consumption) that are borne by or accrue to a third party. Alternatively, extemalities are of ten viewed as the difference between private and social costs (benefits) of production and consumption activities. While most discussions of externalities concentrate on the costs of spillover effects, it is important to recognize that external benefits also exist.

The divergence of social costs (the total costs of all resources used in a particular production activity) from private costs (the resource costs incurred by the specific producer(customer) is at the center of the concept of externality. If social and private costs are identical, then there are no externalities involved; however, if these diverge, there will be a loss in social welfare. The greater the divergence, the greater will be the loss in social welfare. Thus, this divergence becomes the basis for public intervention. Simply put, when external costs exist, a private firm or a firm with operating characteristics of a private firm, e.g., TVA Power, will not allocate its resources and operate in such a way as to maximize benefits to society. The market cannot give the firm the "correct" signals. Public intervention then centers on how to internalize the difference between social and private costs and have it reflected in private decisionmaking--i.e., "internalizing the externalities."

The following example should help demonstrate the divergence of private and social costs and the relationship of this divergence to rational economic behavior. The cost curves for a hypothetical power plant are presented in Figures $1 A$ and 1B. This family of cost curves and the analysis could be applied to soybean production (erosive versus non-erosive), household wastewater handling (polluting septic tank versus non-polluting constructed wetlands), poultry production (polluting litter-handling systems versus non-polluting options), etc. Under rational economic behavior, the firm with polluting processes would have economic incentives to operate the 


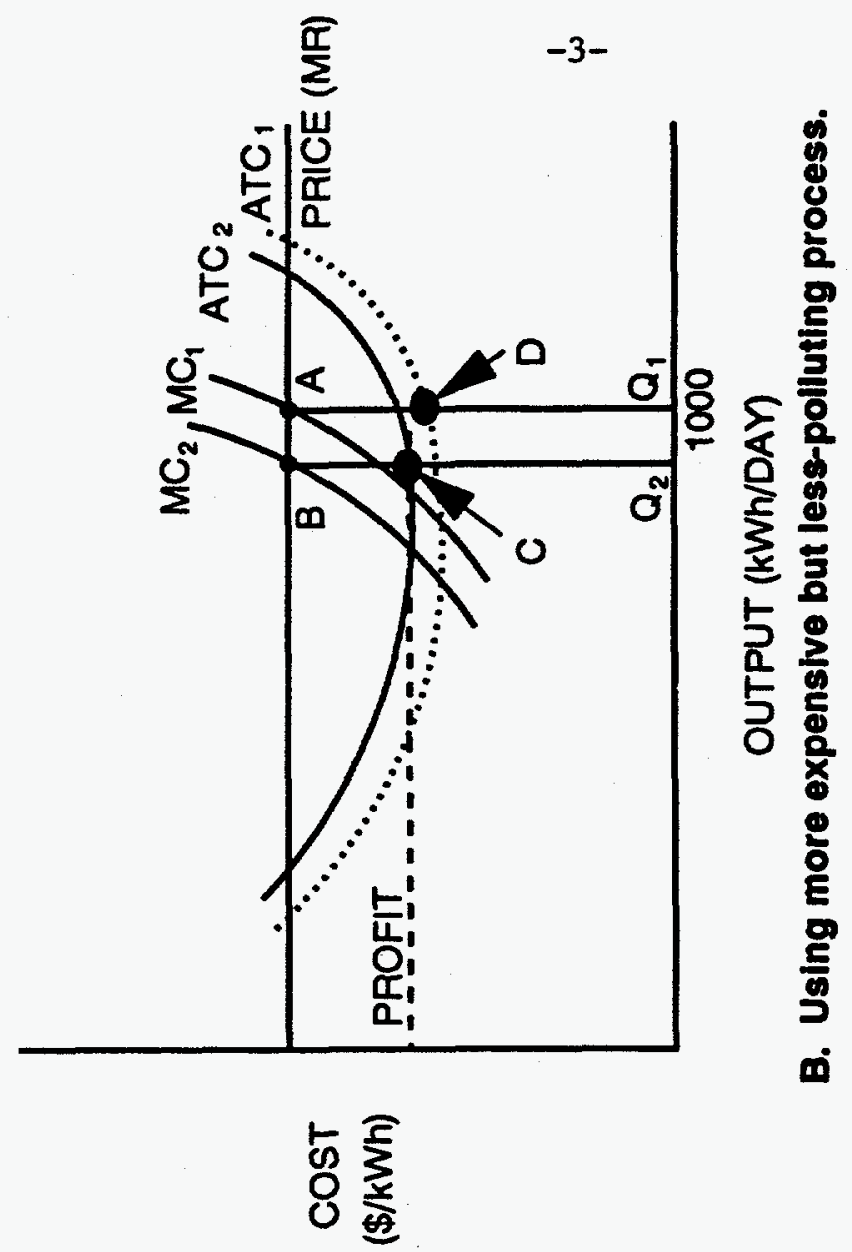

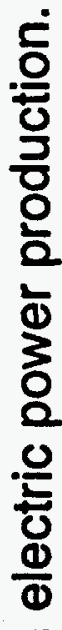

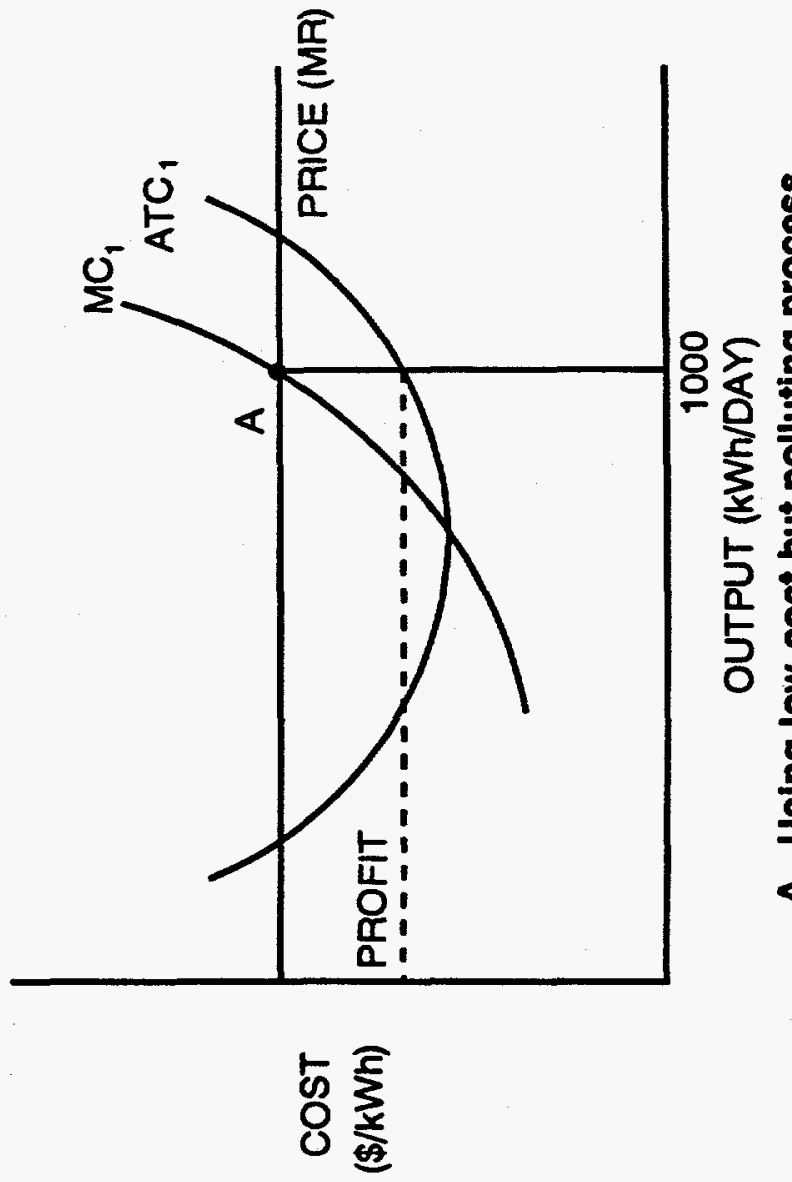


plant at the 1,000 kilowatt-hours-per-day level (Figure 1A). Profits are maximized at point $A$ where the marginal costs equal marginal revenue (price per unit).

However, in this case, external costs are being imposed on third parties because a lower-cost fuel alternative (high-sulfur coal) which results in higher $\mathrm{SO}_{2}$ emissions is being used. Now, consider if public reaction to the $\mathrm{SO}_{2}$ releases (externalities) were to result in regulations that would require the plant to reduce $\mathrm{SO}_{2}$ emissions by burning a more expensive but less polluting coal (Figure 1B). With these former external costs now internalized, costs increase (from $\mathrm{ATC}_{1}$ to $\mathrm{ATC}_{2}$ ); the rational economic behavior level of the operation shifts from $A$ to $B$; and the profit maximizing rate of output falls (from $Q_{1}$ to $Q_{2}$ ), as well as the level of profit. The social cost is the difference between costs at points $C$ and D. The mirror image helps explain why when external costs exist a firm will pollute more than is socially desirable. The point is: as long as external costs can be substituted for private costs, producers and consumers will pursue the polluting option. For example, roadside littering, vehicle abandonment, and illegal dumping are all practiced where the costs of proper disposal (compliance) are higher (real or imagined) than just dumping. Market incentives can and do encourage pollution!

\section{Adjusting Market Incentives--Internalizing the Externalities}

If market solutions are resulting in undesirables (externalities), a range of tools (policy options) is available to prevent the substitution of social costs for private costs, therefore increasing total social welfare or compensating for a loss of welfare. 1 These choices range from the voluntary approaches (the "carrots") to the command and control options (the "sticks"). The three general approaches to internalizing external costs and benefits are: (1) education, (2) altering market incentives, and (3) bypassing market incentives.

\section{Education}

Education internalizes costs by raising the social consciousness and sensitivity or by reducing the risks associated with use. Public service announcements and public educational activities, such as anti-1ittering campaigns or soil conservation demonstrations, center on altering economic

1. The economic definition of pollution (or external cost existence) requires that the action of one agent cause a $10 s s$ of welfare to another agent, and that this $108 s$ of welfare is uncompensated. If these conditions are not met, there is no economic pollution and no basis for policy to modify market behavior. There is no economic problem, but there may be environmental pollution. 
incentives. Increased public awareness and sensitivity encourage consideration of a broader range of alternatives and tradeoffs. In a sense, educational activities are indirect subsidies to alter markets, but changes in behavior generally move at a glacial pace. Demonstrations enhance the market-altering ability of pure education/awareness efforts by reducing the costs of acquiring information, as well as by reducing the degree of risk associated with adoption of the less polluting technology.

\section{Altering Market Incentives}

The altering of market incentives can be approached through several policy tools-the efficiency and feasibility of which are of ten situation-specific.

Taxation--This policy tool has been explored as a way to equate private and social costs and benefits. However, it has had problems in the United States. For such an option to be effective and efficient, accurate estimates of the damage (externality) must exist. Generally, taxes have been more successful in adjusting benefit externalities. Forcing "free riders" to pay for social actions, where it is difficult to exclude consumers, is the most common example of successful use of taxation to correct externalities.

Emission Charges--These charges are direct fees assessed on pollution quantities being released. The fees force reconsideration of the efficiency and production decisions. Examples of emission charges range from fees charged for $\mathrm{SO}_{2}$ releases at power plants and release of heated water from industrial facilities to the deposits required on returnable bottles. In each instance, the charge works to internalize costs.

Emission charges must be set at levels that significantly alter costs in order to force reconsideration of production and efficiency decisions. If not, the polluter will simply pay the charges (if apprehended) and continue to substitute social costs for private costs.

Subsidies--Supports or subsidies have long been used to alter market incentives and to induce adoption of less polluting options. Examples of direct subsidies most of ten cited are agricultural soil conservation programs and wastewater treatment grants. While subsidies are, in fact, negative taxes, their objective is not a direct income transfer but rather a means of reducing the risk of technology adoption and the compounding of that risk by the lumpiness of initial investments. The route of subsidies for altering market incentives can be very indirect, such as public funding of electric vehicle research or environmental education programs. As with taxes, the information and administration requirements for use of direct subsidies are very high relative to indirect subsidies. Also, subsidies are prone to being capitalized into the value of assets. This raises equity considerations and of ten leads to even greater market distortions.

Marketable Permits-Use of market-based instruments (permits) is a recent innovation for internalizing some external costs. The basic features of marketable pollution permits are the establishment of levels of polluting discharges, e.g., 1990 levels for $\mathrm{SO}_{2}$ emissions, and the issuing of permits for these emissions in manageable units or denominations, e.8., per ton $\mathrm{SO}_{2}$. 
Marketable permits with established emission limits or ceilings have advantages over emission charges, standards, subsidies, and taxes. The most commonly cited advantages are that marketable permits: (1) promote cost minimization; (2) facilitate new industry entrants and industry adjustments; (3) provide opportunities for non-polluting entities, including municipalities and environmental advocacy groups, to participate; (4) provide a built-in mechanism for inflation adjustment; and (5) foster technology development (reduce cases of technological "lock-in").

The three types of permit systems are:

1. Ambient Permit System. Based on "receptor point" exposures.

2. Emissions Permit System. Based on sources of emissions.

3. Po1lution offset System. Where permits are issued for a trade zone on the basis of emission quantities but with receptor point standards.

Each permit system has its advantages and disadvantages which generally center on the relative ease of implementation and on effectiveness and efficiency tradeoffs. Generally, the "Emissions Permit System" is considered easier to implement than the "Ambient Permit System." The "Pollution Offset System" has evolved as a synthesis of the other two.

Emissions Irading Program/Emission Reduction Credits--Less than satisfactory results under the standards, taxes, and emission permit systems institutionalized under the Clean Air Act of 1970 led to the design of alternatives to improve alteration of market incentives. These innovations were authorized in the 1977 amendment to the Act. The "internalizing" innovation of note is the emissions trading program. This market-based program operates through emission reduction credits earned in non-attainment areas. The credits are for reductions in excess of proscribed standards, and they technically reflect "reasonably available control technologies" (RACT) for existing plants and the "lowest achievable emission rate" (LAER) for new construction.

Basically, reduction credits earned can be traded four ways: "offsets," "bubble," "netting," and "banking." Each of these trading options depends on the definition of the non-attainment area and the trading zone or market. Offsets appear to most commonly refer to allowing new sources to be established if credits can be secured elsewhere in the region to "offset" the increase. The bubble is similar but is envisioned as a glass dome covering several sources of emissions. If one source exceeds the RACT standard, it can compensate by securing emission reduction credits from elsewhere in the "bubble." A "bubble" may be composed of several plants or only one plant. Netting has been used in situations where plants are being modernized and the stricter LAER standards of new construction are unattractive. In such a scenario, credits earned elsewhere in the plant could be used to "net out," thus maintaining or reducing total source emissions at the site. Banking simply allows accumulation of emission credits for use in any form of emission trading. 
Marketable permits and emission reduction credits are gaining in popularity because they: (1) tend to result in better air quality, (2) result in significant cost savings, (3) assist regions that would otherwise suffer economically, (4) stimulate development of abatement technology, and (5) result in lower administration costs.

\section{Options for Bypassing Market Incentives}

Options for bypassing market incentives are the "sticks" or command and control regulations. Standards are set, and, with monitoring, stop orders and/or heavy fines are levied when violations are found. The costs are internalized by imposition of the cost of compliance on the polluter. Frequently, initial permits and annual 1icense fees are used to establish and maintain systems for monitoring and administering control regulations. The standards approach is frequently criticized for reliance on health-based criteria rather than on environmental damage and because the resulting solutions are not cost-sensitive.

\section{The Electric Power Industry and Externality Valuation:}

\section{The Current Debate}

A brief review of the electric power industry's current externality debate reveals that the controversy is a special application of the concept. The issue revolves around how to value or "monetize" environmental externalities for use in the siting and choice of technology decisions in planning new power production facilities. The emphasis is on incorporating market incentives into the initial investment decision--not into short-rum operating decisions. However, the initial choice of technology and the associated capital investments to meet regulations and standards obviously dictate short-run environmental performance.

\section{Optimum Level of Pollution}

Much of the debate hinges on the concept of the economic optimum level of pollution and what this holds for valuing externalities below this optimum level. An extension of the theory illustrated in Figures $1 \mathrm{~A}$ and $1 \mathrm{~B}$ on page 3 is presented in Figure 2 (following page) for economy of presentation.

Figure 2 reflects the marginal derivatives of the average cost concepts of the firm in Figure 1A. The "marginal net private benefits" (MNPB) curve reflects the net benefits (price minus marginal cost) to the power plant for each kilowatt-hour produced less the cost of producing each additional unit. At low levels of production, the net benefits are high per unit of output. However, benefits fall throughout the relevant range because of competitive pressures and diminishing productivity, i.e., each additional 


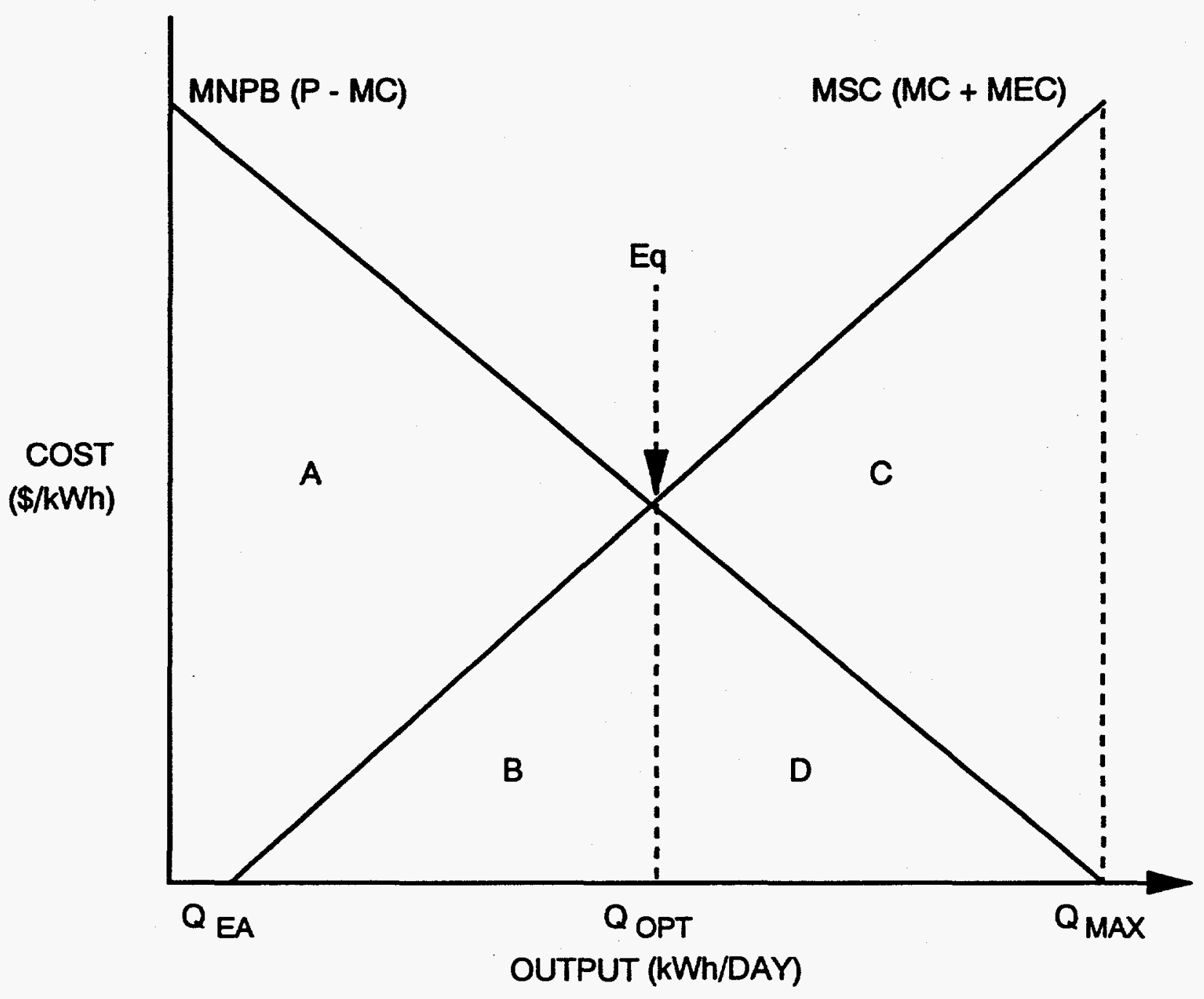

Figure 2. Definition of the economic optimum level of pollution in electric power production. 
gain in pollution abatement is increasingly difficult to achieve. The economic incentive to the plant management, other things being equal, is to produce/expand output as long as private benefits exceed costs (up to QMAX).

Potential environmental impacts (and/or wastes) will be relatively low at low rates of power production and may only be temporary externalities due to the assimilative ability of the natural environment (point QEA). This is the point where "marginal social costs" (MSC) become relevant. NOTE: The deviation of the MSC curve has an underlying assumption central to the current debate. The MSC reflect the costs to be incurred from using the most cost-effective pollution control technology for each level of output and the "marginal external cost" (MEC). If the technology used is not least-cost, a net $10 s s$ of social welfare will occur.

The "socially optimum level of economic output and pollution" (QOPT) is defined by the equating of the MNPB with MSC (point Eq). Since the goal of society is to maximize the sum of the benefits minus the sum of total resource costs, Area $A$ is the largest area of net benefits possible and therefore defines the optimum level of output. Area B is the economic damage incurred in producing this optimum level of output and reflects the optimum externalities in optimizing social welfare. Area $D$ is the net private benefits that are socially unwarranted; and when combined with Area $C$, represents the area of non-optimal externality that should be removed/prevented by regulation.

Definition of the economically optimum level of pollution has several major implications. First, the physical presence of pollution does not mean that economic pollution exists. Second, if economic pollution does exist, it is unlikely that it should be completely eliminated. Third, reflecting the First Law of Thermodynamics, zero waste is an impossibility, but zero quantity of waste affecting the environment is plausible. Fourth, zero economic pollution does not require zero economic activity. Fifth, in a static world, there can be a significant difference between the economist's optimum and the scientist's solution to pollution problems; however, in a dynamic world, the two probably draw closer together as tradeoffs are evaluated. Sixth, the nature and extent of the damages from alternative technologies, i.e., the damage function, must be known before socially optimum solutions to externalities can be designed. Finally, if people do not notice or care about the physical effects of wastes and pollution, the socially optimum level of economic pollution will be correspondingly higher. At the extreme that "people don't care," there will be no MSC! This last point is especially relevant to the current externality debate.

\section{The Current Debate}

Within the last five years, selected state public utility commissions have begun to assign dollar values to "monetize" certain environmental damages for electric utility planning purposes. These externality values are for the "residual" externalities after designs have incorporated the appropriate technology to bring the estimated emissions into compliance with existing standards and regulations. The basic motivation appears to be that since all electric power options are not equally disruptive to the environment, there needs to be a "leveling of the playing field." 
Previous attempts to address these differences in environmental impacts have relied primarily on qualitative data/values and have resulted in subjective decisions. In the hard-versus-soft analyses, supply-side considerations, i.e., low-cost or least-cost, have dominated, with coal and nuclear being the technologies of choice. NOTE: The National Environmental Policy Act requires ranking of power production sites, technologies, and fuels according to their respective costs and benefits. Thus, demand-side options (alternative fuels, conservation choices, environmentally beneficial options, etc.) tend to have higher direct costs because of the lack of opportunity to include external benefits into the cost:benefit analysis. Therefore, "leveling of the playing field" by valuing "residual" externalities (both costs and benefits) allows the higher costs of the more environmentally-friendly demand-side options to be offset by "avoided" costs. The higher the costs of the supply-side options, the higher will be the "avoided" costs.

The question then shifts to what are the residuals and what are their values?

\section{Valuing Externalities}

By definition, externalities are outside the market; therefore, no readily observed prices are available for estimating their value. Externality valuation, in both theory and practice, is in its relative infancy, despite the efforts of natural resource economists over time to measure the value of aesthetics, wildlife, hunting, fishing, other outdoor recreation, wetlands, etc. In general, the findings and results have not been accepted as "robust" and have to be estimated in each case.

Approaches commonly used to value amenities and natural resources include:

1. Weighted Preference Ranking. Developed by use of expert pane1s and/or resource users, e.g., deer hunters, through a Delphi process. The weights and preferences can then be used to develop a "monetized" value of the resources.

2. Contingent Valuation. Approaches resource valuation basically by surveying users and potential users on their willingness to pay for resource use or willingness to accept compensation if the resource use is denied.

3. Direct Impact Assessment. Is based on estimating the dollar value associated with the impacts (damages or benefits) of any given activity. For example, in valuing hunting resources, hunters have been surveyed as to the total cost incurred, by component, of a hunting "experience," i.e., travel costs, lodging, leases, licenses, etc. The sum of these is then used as an estimate of what value hunters place on the resources used. 
In "monetizing" pollution impacts, each damage or benefit is traced out and the value to each resource is then directly estimated and summed to obtain net externality values. However, sufficient data are rarely available on the nature of all damages or on the initial condition of the resources for a "clean" application of the direct impact approach.

4. Revealed Preference. Approach suggests that the values of the externalities are revealed by public policies. The costs incurred to implement these policies are then, in fact, the appropriate values of the externalities. Thus, the choices of control technology employed and the standards established will greatly influence the final estimated value of externalities.

5. "Adders" Concept. A combination of the "Direct Impact" and the "Revealed Preference" approaches. Concept basically amounts to inflating the estimate of the most stringent and highest cost control by, for example, 20 percent. If benefits or offsets, e.g., a new forest planted as a carbon sink, are claimed, these are netted in the calculations.

"Revealed Preference" and the "Adders Concept" are difficult to separate as distinctly different approaches. Advocates of both encourage use of high values because of the desirability of erring on the risk averse side of environmental and health protection. These approaches are the most contentious dimensions of the externality valuation debate.

\section{Which Externalities to Value}

There is agreement among the debaters that "residual" externalities do exist. However, there is considerable disagreement as to whether or not these residuals are unpriced externalities that should be internalized.

Advocates of residual externality valuation appear to rely on the "Revealed Preference" theory for the basic philosophy of their argument. The reasoning roughly follows that legislators and regulators, reflecting the electorate's willingness to pay or to be compensated, have issued standards and regulations to internalize those externalities readily identifiable. However, the estimation of damages caused by environmental externalities is complicated by atmospheric, biological, chemical, geophysical, ecological, and physiological relationships over time and space, as well as by socioeconomic and cultural considerations. Therefore, there is no practical way to explicitly account for these in standards and regulations. Accordingly, valuing residuals is advocated as risk averse policy that leans toward environmental and human health protection.

The opponents of valuing these residuals appear to draw most of their argument from the concept of optimum pollution and the resulting implication that there is no optimum level of externality consistent with maximizing social benefits (refer again to Figure 2 on page 8 ). They contend that attempts to internalize optimum externalities will result in a 
net loss in social welfare. Likewise, they argue that reliance on the highest-cost method of control as a way to value residuals (for use as "adders" or as a proxy for full resource cost) violates the concept of the MSC as a summation of the least-cost techniques of control and results in a net $10 s s$ of social welfare.

Opponents of residual valuation also are critical of the equating of environmental and health impacts with environmental externalities. In addition, opponents hold that state public utility commissions (PUCs) are not the appropriate agencies to be making residual externality valuation decisions. One element of this criticism is that PUCs do not have the expertise to monitor damages or to value externalities. The other element contends that it is inappropriate to try to solve global externality problems on an individual site and state basis. The tendency, opponents argue, is to create regional comparative disadvantages.

\section{Summary of the Current Debate and Implications for IVA}

The current debate in the electric power industry may be couched in terms of externality valuation techniques, the concept of residual externalities, and maximum social welfare. However, the bottom line is environmental philosophy. The advocates of the "greener" perspective contend that valuation of only explicit danages and the difficulty of quantifying benefits of the more environmentally-friendly options lead to a technological lock-in on resource exploitative technologies (coal and nuclear). The playing field is not level.

Opponents contend that attempts to level the playing field (by "adders" and "monetization" of loosely defined externalities) are theoretically inappropriate or suboptional and will result in losses of social welfare.

In the absence of Federal intervention into the issue, it will remain a contentious issue for some time to come. A brief review of externality valuation in the 7-state TVA region reveals a very conservative and supply-side friendly philosophy. It does not appear that residual externality valuation will be an integral part of TVA siting and choice of technology decisions in the immediate future unless initiated by TVA's recent adoption of Integrated Resource Planning (IRP).

\section{Externalities and the IVA Environmental Research Center}

Drawing on the background developed for this discussion document, observations will be offered on the relevance of externalities to the IVA Environmental Research Center, its programs, and its activities. These observations are not intended to be all inclusive or micro in detail; that is beyond the scope and intent of this paper. But rather, the purpose is to stress the broad implications of the concept for the Center and the major programatic opportunities identified by this analysis. 


\section{Relevance of Externalities to the TVA Center}

The existence of economic externalities is the philosophical base for the establishment of public sector research and development programs and attendant activities focusing on environmental problems. Externalities arise because of the market's inability to prevent private and social costs from diverging, thus providing the basis for government intervention. Such intervention on behalf of society to prevent the substitution of social costs for private costs requests a revealed preference for social objectives or actions that the market cannot recognize or communicate. In a very real sense then, society, the electorate, or its representatives are the constituency for environmental research addressing externalities not easily internalized to polluters. Even in cases where externalities have been internalized by policy actions, cost-effective advances in technology or approaches for improving the effectiveness and efficiency of policy actions will result in a gain in net social welfare. Furthermore, the insidious nature of pollution creates a need for institutions that monitor conditions and are in a position to proactively adjust research and development agendas before site specific externalities become global in nature.

Externalities also can provide the conceptual framework for the selection of high-payoff areas of environmental research. The physical existence of pollution alone is not sufficient justification for research. Gains in net social welfare will accrue to research and action efforts targeted to resource use (abuse) problems with significant economic externalities. The broader the applicability of the solutions developed, the greater will be the gains in net social welfare--but that may render identification of potential paying customers extremely difficult.

Research solutions to be pursued should be subjected to a "plausibility check" with respect to externalities. The hypothesized solution should be examined for consistency with the policy options available for implementation. For example, if a proposed solution would require a specific policy action to successfully alter market behavior (to internalize the externality), this consideration should be reflected in calculating the probability of success. Likewise, proposed projects should explicitly consider options to alter externalities as the technology transfer program is visualized and programmed for future action. This is especially relevant because of the short "shelf life" of technical developments in this arena where the demand for products and services is regulation driven. The logical extension of this line of reasoning is that research and development institutions will have to become proactive in policy development and implementation to ensure that maximum benefits accrue to the research agenda adopted and pursued.

\section{Procrammatic Implications and epportunities}

Review of the concept of externality and some of its applications suggest:

1. Accurate estimates of the incidence and magnitude of resource damages, as well as benefits, associated with resource uses are critical to the selection, design, and implementation of control strategies. Likewise, 
the development of technologies and methodologies for measuring and monitoring such impacts have a parallel demand. Such information and technology should be especially marketable internally as TVA implements the recently adopted IRP approach to its power production and planning programs.

2. The concept of "offsets" and "emission reduction credits earned" for trading purposes or for incorporation into IRP offers significant opportunities for research. The current efforts to evaluate the potential of new forests (plants and soils) for sequestering carbon is directly applicable. The potential of alternative fuels for integration into IRP, such as the study of short-rotation woody plantations, should be highly marketable.

3. Marketability of research can be significantly enhanced by identifying and exploiting the potential of secondary and tertiary impacts, both damages and benefits. Avoided costs, via benefits, become increasingly important to the development of effective and efficient full-resource cost solutions.

4. Packaging of research findings for transfer and adoption can be enhanced by specification of the policy tool, or mix of tools, that should be most effective. Policy recomnendations, however, should be quantitatively evaluated for both direction and magnitude of impact.

5. The demand for environmental technology is regulation driven. Effective needs analysis will require investment in specialized resources to "mine" the issues and be "out front."

6. It appears that global externality concerns/problems addressed from a regional perspective will be difficult to market. However, such activities can earn "leadership credits." Simply, it is hard to internalize externalities across geographical and political boundaries-especially national boundaries.

7. Research premised on complete elimination of pollution or wastes is probably "overkill," and the probability of results with cost effectiveness, at the margin, is very low. 


\section{Selected Bibliography}

Various publications and articles with numerous commonalities were used in developing the background for this discussion paper. Since no citations were employed, a "selected bibliography" is presented; the publications referenced here were selected for breadth of coverage of the subject and liberal use by the author.

Carlson, Gerald A., David Zilberman, and John A. Miranowski (eds.), Agricultural and Environmental Resource Economics, Oxford University Press, New York, 1993.

Consumer Energy Council of American Research Foundation Environmental Externalities Project, Incorporatine Environmental Externalities Into Utility Planning: Seeking a Cost-Effective Means of Assuring Environmental Quality, Consumer Energy Council of American Research Foundation, July 1993.

Energy Research Group, Inc., Environmental Externalities: An Issue Under Critical Review, Edison Electric Institute, Washington, D.C., May 1992.

Energy Research Group, Inc., Environmental Externality: Testimony Summaries, Edison Electric Institute, Washington, D.C., July 1992.

Joskow, Paul L., "Dealing With Environmental Externalities: Let's Do It Right," Issues and Trends Briefing Paper, Edison Electric Institute, Washington, D.C., Number 61, 1992.

Pearce, David W., and R. Kerry Turner, Economics of Natural Resources and the Environment, The Johns Hopkins University, Baltimore, Maryland, 1990 .

Randa11, Alan, "What Practicing Agricultural Economists Really Need To Know About Methodology," American Journal of Agricultural Economics, Vo1. 75 (75th Anniversary Issue), October 1993. 